\title{
A Rare Case of Intractable Laryngeal Sarcoidosis: A Case Report
}

\author{
Masaru Miyazaki $^{1,2}$ Seiji Haraoka ${ }^{3}$ Toshifumi Sakata ${ }^{2}$ Takafumi Yamano ${ }^{1}$ \\ 1 Section of Otorhinolaryngology, Department of Medicine, Fukuoka \\ Dental College, Fukuoka-shi, Fukuoka, Japan \\ 2 Department of Otorhinolaryngology, Fukuoka University Hospital \\ and School of Medicine, Fukuoka, Japan \\ ${ }^{3}$ Department of Pathology, Fukuoka University Chikushi Hospital, \\ Address for correspondence Takafumi Yamano, MD, PhD, Section of \\ Otorhinolaryngology, Department of Medicine, Fukuoka Dental \\ College, 2-15-1 Tamura, Sawara-ku, Fukuoka-shi, Fukuoka 814-0193, \\ Japan (e-mail: yamano@college.fdcnet.ac.jp).
} Chikushi, Fukuoka, Japan

Int J Pract Otolaryngol 2020;3:e6-e9.

\begin{abstract}
Laryngeal sarcoidosis is rare, and reports of recurrences after treatment are even rarer. A 49year-old Japanese female patient visited our clinic with a 7-day history of dysphagia. Her medical history included sarcoidosis involving the cervical lymph nodes. Endoscopic examination revealed a diffusely swollen epiglottis and bilateral edema of the arytenoids. Corticosteroids and antibiotics were administered, but the laryngeal edema did not subside. Contrast-enhanced computed tomography imaging revealed bilateral low-density areas in the arytenoids. Therefore, we performed bilateral arytenoid biopsy under direct laryngoscopic guidance. The histopathology showed noncaseating epithelioid cell granulomas with moderate to severe chronic inflammatory infiltration; based on these findings, we diagnosed the patient as having laryngeal sarcoidosis. While the laryngeal edema did not recur for several months, arytenoid edema recurred 9 months after systemic steroid therapy. The patient's medical history of sarcoidosis of other organs as well as the

\section{Keywords}

- laryngeal sarcoidosis

- laryngeal edema

- epiglottitis

- noncaseating epithelioid granuloma presentation of edema of a supraglottic lesion and histopathological findings of noncaseating epithelioid cell granulomas led us to make the diagnosis of laryngeal sarcoidosis again. Laryngeal sarcoidosis is an important consideration in the differential diagnosis of laryngeal edema, as its therapy and clinical course are different from those for other diseases that present with laryngeal edema. A cautious follow-up of patients diagnosed as having laryngeal sarcoidosis is needed, because in rare cases, the laryngeal edema can become worse over time even after therapy.
\end{abstract}

\section{Introduction}

Sarcoidosis is a multisystem, chronic granulomatous disease of unknown etiology that predominantly affects the lungs. Sarcoidosis of the larynx is very uncommon. The prevalence of laryngeal involvement among sarcoidosis patients is $0.33 \%{ }^{1}$ Laryngeal findings of the laryngeal sarcoidosis are generally edema of the epiglottis, arytenoids, and false vocal cords. ${ }^{1}$ Systemic corticosteroids are commonly used to treat laryngeal sarcoidosis. ${ }^{1}$ There are conditions of the cases that are treated but also exacerbate or recur. ${ }^{2-5}$

received

November 18, 2019

accepted

February 13, 2020
DOI https://doi.org/

10.1055/s-0040-1710349.

ISSN $2569-1783$.
In clinical practice, laryngeal edema is frequently seen in acute epiglottitis, laryngitis, and laryngeal allergy. In the case of acute epiglottitis or laryngitis, it is particularly necessary to pay attention to acute airway obstruction. In some cases, tracheostomy is required to resolve upper airway obstruction in laryngeal sarcoidosis. ${ }^{1}$ Differential diagnosis of laryngeal sarcoidosis is important because its treatment and course are different from other diseases that cause laryngeal edema.

Herein, we report a case of laryngeal sarcoidosis that showed exacerbation of laryngeal edema 9 months after systemic steroid therapy. In addition, we summarize long-

Copyright $\odot 2020$ Georg Thieme Verlag License terms KG Stuttgart · New York

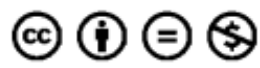


term follow-up reports from previously described cases of laryngeal sarcoidosis and compare treatments with exacerbation or recurrences.

\section{Case Report}

A 49-year-old Japanese female patient visited our clinic presenting with progressive dysphagia that had lasted for 7 days, triggered by environmental exposure to a high level of atmospheric particulate matter (PM) with diameters $<2.5 \mu \mathrm{m}$ $\left(\mathrm{PM}_{2.5}\right)$. She described experiencing this symptom during the same timeframe every year. Her medical history revealed an episode of sarcoidosis of the cervical lymph node that occurred 7 years earlier and allergic rhinitis caused by pollen from Japanese cedar and cypress. She was subsequently admitted to the Department of Otorhinolaryngology at Fukuoka University Chikushi Hospital (Fukuoka, Japan). There were no significant findings in the oral cavity and no swelling of the neck. Endoscopic findings revealed a diffusely swollen epiglottis and

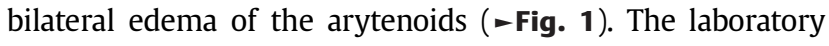
results indicated the following values: white blood cells (WBCs): $8,600 / \mu \mathrm{L}$ (71.3\% neutrophils and $0.2 \%$ eosinophils); C-reactive protein (CRP): $0.03 \mathrm{mg} / \mathrm{dL}$; and total immunoglobu$\operatorname{lin} \mathrm{E}(\mathrm{IgE}): 132 \mathrm{IU} / \mathrm{mL}$. Specific IgE tests were performed for the following individual antigens: mites: $9.16 \mathrm{UA} / \mathrm{mL}$; house dust: $7.87 \mathrm{UA} / \mathrm{mL}$; Japanese cedar pollen: $18.6 \mathrm{UA} / \mathrm{mL}$; Hinoki cypress pollen: $5.55 \mathrm{UA} / \mathrm{mL}$; orchard grass: $34.4 \mathrm{UA} / \mathrm{mL}$; and ragweed: $2.85 \mathrm{UA} / \mathrm{mL}$. Diagnoses of laryngeal allergy, acute epiglottitis, and laryngitis were considered, and corticosteroids (methylprednisolone at $125 \mathrm{mg} / \mathrm{d}$ for 8 days) and antibiotics (ceftriaxone hydrate at $1 \mathrm{~g} / \mathrm{d}$ for 3 days) were administered intravenously. Additionally, antihistamines (fexofenadine and montelukast) were given orally. Because the swelling and edema of the epiglottis and larynx showed no improvements, a contrast-enhanced cervical computed tomography (CT) scan was performed to rule out tumors. Low-density areas were found in bilateral arytenoids, but no tumor-like lesions were observed ( - Fig. 2). No swelling of the lymph node was detected in the head and neck. Given that there was the episode of

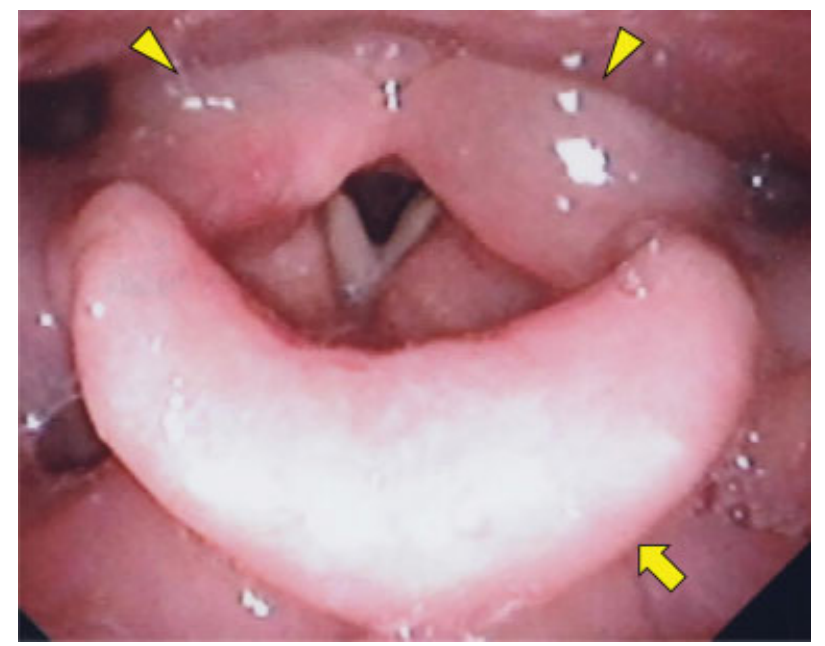

Fig. 1 Endoscopic findings. The epiglottis (arrow) is diffusely swollen and the bilateral arytenoids (arrowheads) show edema.

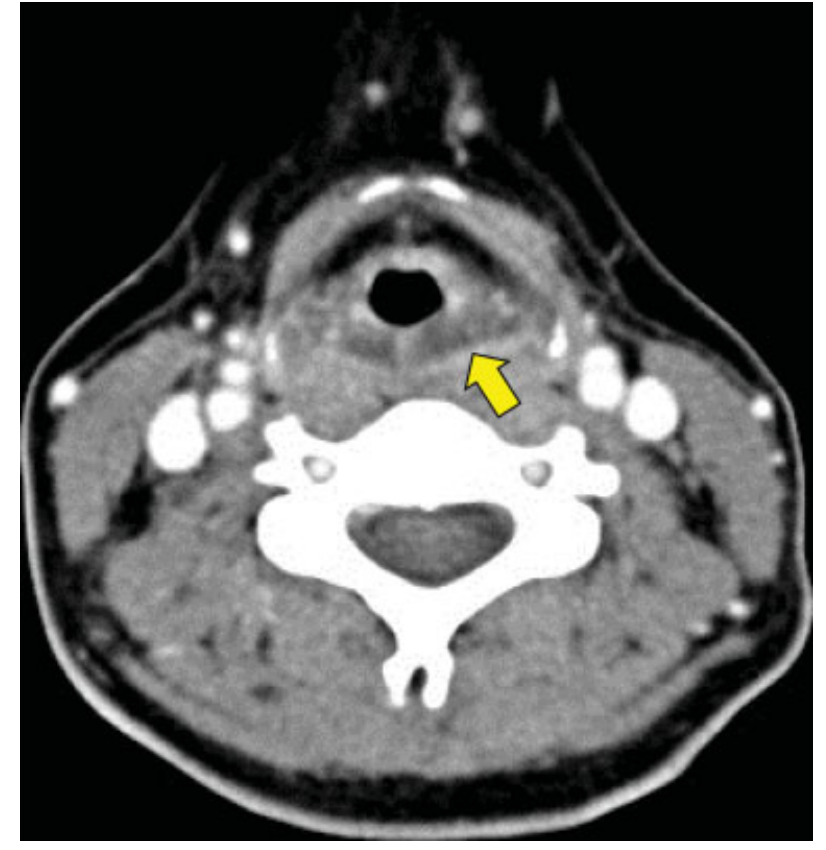

Fig. 2 Contrast-enhanced cervical CT. Low-density areas are seen bilaterally in the arytenoids (arrow); although, no tumor-like lesions are observed. CT, computed tomography.

sarcoidosis of the cervical lymph node, we considered a diagnosis of laryngeal sarcoidosis. Corticosteroids (prednisolone at $30 \mathrm{mg} / \mathrm{d}$ for 7 days) were administered again. However, as no improvement of the larynx was seen, direct laryngoscopyguided biopsies under general anesthesia were ordered to establish the diagnosis of laryngeal sarcoidosis and to rule out malignancy and other causes of upper-airway disease. During direct laryngoscopy, edema of the submucosa of the arytenoids was observed, and surgical specimens from the arytenoids were obtained bilaterally. The histopathological findings showed noncaseating epithelioid-cell granulomas with moderate to severe chronic inflammatory infiltrates (-Fig. 3). Ziehl-Neelsen staining showed no presence of acidfast bacilli, and Grocott's and periodic acid-Schiff (PAS) reaction staining revealed no fungal organisms. There was no evidence of malignancy. A diagnosis of laryngeal sarcoidosis was established. Her respiratory condition was stable although the laryngeal edema did not improve, so treatment was not performed after biopsy and follow-up included observations only. However, the edema of the arytenoids exacerbated 9 months after systemic steroid therapy. We searched for sarcoidosis lesions in the lungs and mediastinum after diagnosis of laryngeal sarcoidosis, but none were found.

\section{Discussion}

The patient's medical history of sarcoidosis of other organs as well as the presentation of edema of a supraglottic lesion and histopathological findings of noncaseating epithelioid cell granulomas led us to diagnose this case as laryngeal sarcoidosis. Clinical differential diagnoses for laryngeal edema include laryngeal allergy, acute or infectious laryngitis, laryngitis due 


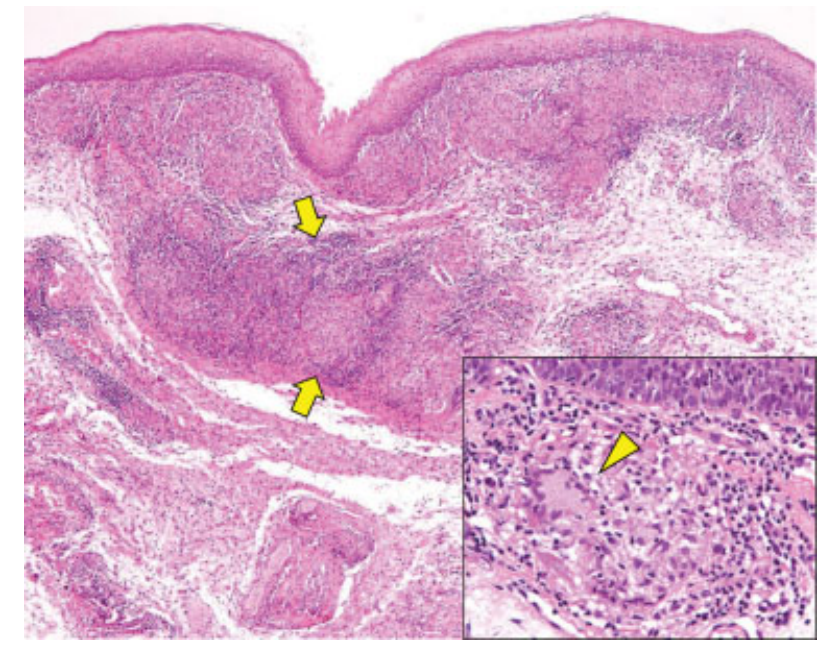

Fig. 3 Histopathology with hematoxylin and eosin staining. The section shows noncaseating epithelioid cell granulomas with moderate to severe chronic inflammatory infiltrates (arrows). Langhans giant cells (arrowhead) are also observed. No necrotic lesions are seen. to inhalation of noxious fumes, and angioedema, and we considered these diagnoses at the initial visit. The patient's chief complaint was dysphagia, and her symptoms did not include dramatic pain, acute infectious inflammatory reactions, or laboratory findings of elevated WBC, CRP, or fever. Moreover, she had a history of allergic rhinitis due to pollen from Japanese cedar and cypress and tested positive in the radioallergosorbent test. Given her history of severe exposure to $\mathrm{PM}_{2.5}$, we also considered laryngitis due to inhalation of noxious fumes. $\mathrm{PM}_{2.5}-\mathrm{a}$ type of air pollutant characterized by small particle size, comprising a mixture of particles that include black carbon, nitrate, sulfate, and automobile exhaust particles-can aggravate infections of the upper respiratory tract. The patient was admitted to our hospital in the Department of Otorhinolaryngology for the administration of medications to the upper airway and to avoid inciting antigens. Systemic steroids, antibiotic agents, and antihistamine medications were administered to the patient. However, the arytenoid edema showed no improvement after more than 2 months of therapy. The patient's clinical course did not fit the

Table 1 Treatments and clinical courses in laryngeal sarcoidosis case reports that showed no sign of exacerbation or recurrence for 6 months or longer

\begin{tabular}{|c|c|c|c|}
\hline Lead author & Year & Effective therapy & Clinical course \\
\hline Kirschner $^{15}$ & 1976 & Prednisone 60 and $80 \mathrm{mg}$ alternate day & The patient remained asymptomatic for 20 mo \\
\hline Levey $^{5}$ & 1979 & Cortisone & The patient showed recurrence 46 months later \\
\hline \multirow[t]{2}{*}{ Weisman $^{16}$} & \multirow[t]{2}{*}{1980} & Steroids over a 10 -d period & The patient showed no recurrence 18 mo after diagnosis \\
\hline & & Prednisone $60 \mathrm{mg} / \mathrm{d}$ & The patient showed no recurrence 12 mo later \\
\hline \multirow[t]{4}{*}{ Bower $^{4}$} & \multirow[t]{4}{*}{1980} & Prednisone $60 \mathrm{mg} / \mathrm{d}$ systemically & $\begin{array}{l}\text { The patient showed improvement over a 2-mo period } \\
\text { and no recurrence } 3 \text { y later }\end{array}$ \\
\hline & & $\begin{array}{l}\text { Prednisone } 30 \mathrm{mg} \text { twice a day and } \\
80 \mathrm{mg} \text { alternate day }\end{array}$ & $\begin{array}{l}\text { The patient showed remission with the initial therapy anc } \\
\text { maintenance therapy, but recurrence when the steroid } \\
\text { was reduced at } 15 \text { mo }\end{array}$ \\
\hline & & Hydrocortisone injected & The patient remained asymptomatic for 20 mo \\
\hline & & Prednisone $60 \mathrm{mg} / \mathrm{d}$ and $80 \mathrm{mg}$ & The patient showed no symptoms for $30 \mathrm{mo}$ \\
\hline Espinosa $^{13}$ & 1984 & $\begin{array}{l}\text { Methylprednisolone sodium succinate } \\
(500 \mathrm{mg}) \text { injected into the larynx }\end{array}$ & $\begin{array}{l}\text { A second laryngeal injection was required } 14 \text { mo later, } \\
\text { and there was marked improvement }\end{array}$ \\
\hline Ridder $^{12}$ & 2000 & $\begin{array}{l}\text { Clofazimine } 100 \mathrm{mg} / \mathrm{d} \text { for } \\
10 \mathrm{~d} ; 200 \mathrm{mg} \text { of clofazimine } \\
3 \text { times a week for } 10 \mathrm{wk}\end{array}$ & $\begin{array}{l}\text { The patient was followed up for a period of } 48 \mathrm{mo} \\
\text { with no recurrence }\end{array}$ \\
\hline Sakamoto $^{11}$ & 2000 & $\begin{array}{l}\text { Resection and dexamethasone } \\
(0.8 \mathrm{mg}) \text { injected }\end{array}$ & The patient had no recurrence as of the 21-mo follow-up \\
\hline Fuso $^{17}$ & 2001 & $\begin{array}{l}\text { Prednisone } 1 \mathrm{mg} / \mathrm{kg} \text {, } \\
\text { tapered by } 2.5 \mathrm{mg} / \mathrm{wk}\end{array}$ & The patient had no symptoms 12 mo after diagnosis \\
\hline $\operatorname{Dean}^{18}$ & 2002 & Steroid inhaler & The patient retained improvement 12 mo after \\
\hline James $^{10}$ & 2004 & Surgical excision with $\mathrm{CO}_{2}$ lasers & $\begin{array}{l}\text { The patient had not had any recurrence } 30 \text { months } \\
\text { postoperatively }\end{array}$ \\
\hline Agrawal $^{9}$ & 2006 & Azathioprine at $100 \mathrm{mg} / \mathrm{d}$ & $\begin{array}{l}\text { The patient had only minimal residual supraglottic } \\
\text { edema after } 12 \text { months }\end{array}$ \\
\hline Palacios $^{19}$ & 2008 & Systemic prednisone & $\begin{array}{l}\text { The patient showed marked improvement } \\
\text { at the 6-mo follow-up }\end{array}$ \\
\hline Delides $^{8}$ & 2015 & Methotrexate $5 \mathrm{mg}$ & $\begin{array}{l}\text { The patient was completely free } \\
\text { of symptoms } 6 \text { mo later }\end{array}$ \\
\hline
\end{tabular}


profile of angioedema, wherein symptoms of swelling slowly increase over a day and resolve over 48 to 72 hours. Differential diagnoses of noncaseating epithelioid cell granulomas include mycobacterium tuberculosis, tumor-related sarcoid reaction, and mycobacterial fungal infections. Tuberculosis of the larynx is usually a granulomatous or ulcerated type in laryngoscopic findings and shows the histopathology of caseous epithelioid granuloma. However, differential diagnosis may be necessary because it may grossly reveal laryngeal edema and may occasionally present histopathologically as noncaseating epithelioid granuloma. ${ }^{6}$ In this case, mycobacterium tuberculosis and infectious mycobacterial fungal disease could be excluded based on the findings of Ziehl-Neelsen, Grocott's, and PAS staining. Sarcoidosis is sometimes observed in tumors of the larynx; in this case, the tumor-related sarcoid reaction was not considered, as no tumor-like lesions were found in cervical CT and surgical findings.

Laryngeal sarcoidosis patients must be cautiously followed up because laryngeal edema can become worse over time after therapy. Steroids are generally used for drug treatment in laryngeal sarcoidosis, but standard dosages and administration methods have not been established. Treatment with other drugs, such as azathioprine and methotrexate, has been reported. In surgery, the use of $\mathrm{CO}_{2}$ lasers to resect the lesion has also been reported. ${ }^{7} \mathrm{~A}$ review of the medical literature revealed 53 previous reports describing laryngeal sarcoidosis and four reports of laryngeal edema that showed signs of exacerbation or recurrence after therapy. ${ }^{2-5}$ In - Table $\mathbf{1}$, we summarize case reports of laryngeal edemas that showed relatively long remissions of 6 months or longer. Of these, the laryngeal edemas that showed signs of exacerbation or recurrence were found in only two cases, one after 15 months ${ }^{4}$ and the other after 46 months. ${ }^{5}$ All exacerbated or recurrent cases were treated only with systemic steroids. In one case similar to the case reported herein, in which steroidsmethylprednisolone at $125 \mathrm{mg} / \mathrm{d}$ for 6 days and prednisolone at $0.5 \mathrm{mg} / \mathrm{kg} / \mathrm{d}$ for 2 weeks-were administered intravenously, edema of the arytenoid region had worsened after 6 months. ${ }^{2}$ Other cases included one with edema recurrence 15 months after treatment and another case with no recurrence 2.5 years after a regimen of prednisone administered at $60 \mathrm{mg} / \mathrm{d}$ and $80 \mathrm{mg}$ every other day as maintenance thereafter. ${ }^{4}$ Other than the systemic steroid administration, the reported treatment methods that showed remission for more than 6 months include methotrexate, ${ }^{8}$ azathioprine, ${ }^{9} \mathrm{CO}_{2}$ laser ablation, ${ }^{10}$ resection and steroid injection, ${ }^{11}$ clofazimine, ${ }^{12}$ steroid injection, ${ }^{13}$ and radiation therapy. ${ }^{14}$ Three of these patients, who did not receive systemic steroids as the first treatment, were switched to other treatments and improved. ${ }^{8,12,13}$ The dosage, duration, and efficacies of steroid treatments from previous case reports were variable, thus it is not known whether the dose and length of steroid treatment applied in this case were appropriate. If systemic steroid administration is ineffective, other treatments may need to be considered.

\section{Conclusion}

Laryngeal sarcoidosis is important for the differential diagnosis of laryngeal edema, as the therapy and clinical course for laryngeal sarcoidosis are different from other diseases that present with laryngeal edema. A cautious follow-up of patients diagnosed with laryngeal sarcoidosis is needed because laryngeal edema can rarely become worse over time after therapy.

\section{Conflicts of Interest}

None declared.

\section{References}

1 Duchemann B, Lavolé A, Naccache JM, et al. Laryngeal sarcoidosis: a case-control study. Sarcoidosis Vasc Diffuse Lung Dis 2014;31 (03):227-234

2 Tsubouchi K, Hamada N, Ijichi K, Umezaki T, Takayama K, Nakanishi Y. Spontaneous improvement of laryngeal sarcoidosis resistant to systemic corticosteroid administration. Respirol Case Rep 2015;3(03):112-114

3 Mayerhoff RM, Pitman MJ. Atypical and disparate presentations of laryngeal sarcoidosis. Ann Otol Rhinol Laryngol 2010;119(10): 667-671

4 Bower JS, Belen JE, Weg JG, Dantzker DR. Manifestations and treatment of laryngeal sarcoidosis. Am Rev Respir Dis 1980;122 (02):325-332

5 Levey M. Extensive sarcoidosis involving the upper respiratory tract. Int Surg 1979;64(03):73-77

6 Zhao N, Zhang Y, Li K. Rigid laryngoscope manifestations of 61 cases of modern laryngeal tuberculosis. Exp Ther Med 2017;14 (05):5093-5096

7 Edriss H, Kelley JS, Demke J, Nugent K. Sinonasal and laryngeal sarcoidosis-an uncommon presentation and management challenge. Am J Med Sci 2019;357(02):93-102

8 Delides A, Sakagiannis G, Maragoudakis P, et al. Dysphagia caused by chronic laryngeal edema. Dysphagia 2015;30(05):583-585

9 Agrawal Y, Godin DA, Belafsky PC. Cytotoxic agents in the treatment of laryngeal sarcoidosis: a case report and review of the literature. J Voice 2006;20(03):481-484

10 James JC, Simpson CB. Treatment of laryngeal sarcoidosis with CO2 laser and mitomycin-C. Otolaryngol Head Neck Surg 2004; 130(02):262-264

11 Sakamoto M, Ishizawa M, Kitahara N. Polypoid type of laryngeal sarcoidosis-case report and review of the literature. Eur Arch Otorhinolaryngol 2000;257(08):436-438

12 Ridder GJ, Strohhäcker H, Löhle E, Golz A, Fradis M. Laryngeal sarcoidosis: treatment with the antileprosy drug clofazimine. Ann Otol Rhinol Laryngol 2000;109(12, Pt 1):1146-1149

13 Espinosa GA, Hoffmann DF. Laryngeal sarcoidosis. Mil Med 1984; 149(07):417-420

14 Fogel TD, Weissberg JB, Dobular K, Kirchner JA. Radiotherapy in sarcoidosis of the larynx: case report and review of the literature. Laryngoscope 1984;94(09):1223-1225

15 Kirschner BS, Holinger PH. Laryngeal obstruction in children sarcoidosis. J Pediatr 1976;88(02):263-265

16 Weisman RA, Canalis RF, Powell WJ. Laryngeal sarcoidosis with airway obstruction. Ann Otol Rhinol Laryngol 1980;89(1, Pt 1):58-61

17 Fuso L, Maiolo C, Tramaglino LM, et al. Orolaryngeal sarcoidosis presenting as obstructive sleep apnoea. Sarcoidosis Vasc Diffuse Lung Dis 2001;18(01):85-90

18 Dean CM, Sataloff RT, Hawkshaw MJ, Pribikin E. Laryngeal sarcoidosis. J Voice 2002;16(02):283-288

19 Palacios E, Smith A, Gupta N. Laryngeal sarcoidosis. Ear Nose Throat J 2008;87(05):252, 254 